\title{
Damage areas during emergency depressurization of a gas pipeline
}

\author{
Evgenia Varsegova ${ }^{1 *}$, Elena Dresvyannikova ${ }^{1}$, Lilia Osipova $^{1}$, and Renat Sadykov ${ }^{1}$ \\ ${ }^{1}$ Kazan State University of Architecture and Engineering, Zelenaya Ulitsa, 1, Kazan, Tatarstan
}

\begin{abstract}
Main gas pipelines are classified as energetically stressed objects. With an increase in their service life, there appears a need to model emergency breaks and analyze the distribution of the damaging factors of the accident. The main gas pipelines often run near residential areas and cross various communications, therefore possible accidents with gas emissions and damaging factors can negatively affect both the environment and the population. An emergency rupture of a gas pipeline section is numerically modeled in this article. The calculations of intensity of accidental gas emissions outflow and distribution of the accident damaging (the length of the methane jet in unlimited airspace, the range and height of the scattering of the soil and pipe fragments were found). The parameters of free jets of exhaust gas were determined. Such calculation is required during investigation of accidents and development of documents related to the environmentally safe operation of pipeline transport. In case of gas non-ignition, it disperses in the atmosphere with the formation of gas zones. The study of the influence of velocity, density and pressure on the emergency gas emission allows us to determine possible gas contamination zones. Graphs of distribution of static and total pressure over the ejection height, distribution of velocities along the axis of the ejected jet and along the axis of the pipeline were obtained. The ability to evaluate the parameters of free jet flow of natural gas (methane) from a damaged pipeline: the total flow rate, total pressure and flow rate at the rupture point is relevant in solving applied environmental safety problems of gas transportation facilities.
\end{abstract}

\section{Introduction}

Natural gas is one of the most widespread energy source material, so the analysis of possible gas pipeline ruptures determines the technogenic safety of energy objects of gas transport and increases the energy security of the population. Analysis of pipeline transport maintenance is carried out by many authors. In [1], methods of numerical analysis of pipeline transport and safe operation modes are considered. In some works[2,3] analysis of operating experience and mathematical analysis of pipes of polymer and composite materials are presented. The gas-dynamic parameters of gas flow in the gas pipeline, namely velocity, density, and pressure, determine the sizes of gas-contaminated zones, and atmospheric weather conditions affect the movement of the formed gas-air cloud.

In [4], a mathematical model for describing the turbulent distribution of gas emissions through organized pollution sources using the ANSYS (FLUENT) software package was proposed. An express method was developed for immediate environmental assessment taking into account the atmospheric meteorological conditions.

According to available information from Rostekhnadzor, in 2018, 10 accidents took place at gas pipelines, so the number of accidents increased by 2 times compared with that of 2017 (5 accidents). The main contribution to the accident rate at the pipeline transport facilities falls on the linear part. In case of emergency depressurization of the linear part and occurence of a "crack" rupture or "guillotine gap", modern telemechanics and automated control systems of technological process (ACS TP) determine the place of rupture and direct losses. Currently, unmanned aerial vehicles (UAVs) are monitoring both the main transport facilities and the terrain. UAVs are mobile and able to quickly determine the place of leakage, direct losses of the transported product, as well as to monitor the implementation of construction and installation works and emergency response.

If the gap is of wormhole type and small, then the gap place is determined by control devices (gas analyzers, riders) according to gas contamination of the atmosphere. Moreover, the spatio-temporal distribution of the gas-air cloud in the atmosphere is affected by weather conditions and the presence of buildings [5-7]. In [8-10], numerical methods for determining direct gas losses from aboveground, underground, and underwater gas pipelines, the routes of which can pass through settlements are considered. The calculation of

\footnotetext{
Corresponding author: evgeniyav09@gmail.com
} 
distribution of the damaging factors of accidents on gas pipelines allows us to assess with a reasonable degree of probability the possible zones of damage and the degree of the accident consequences $[11,12]$. The theory of risk analysis is based on statistical data [13].

PJSC Gazprom recommends calculating the damaging factors from emergency gas emissions according to the STO Gazprom 2-2.3-351-2009 methodology, in which the zone of the damaging factors action determines the intensity of the outflow. To solve such applied problems, methods of computational fluid dynamics using the ANSYS (FLUENT) software package are widely used. Numerical methods make it possible to most quickly and graphically simulate the turbulent flow of liquids and gases in channels of various shapes and under different conditions of flow organization. The reliability of calculation results is confirmed by experimental data obtained from the analysis of past accidents [14-18]. To determine the profiles of jet velocities and flow turbulence parameters, it is proposed to use the gradient method and the profile method, the essence of which is described in [19]. The use of turbulence models to solve these tasks is described in [20-22].

\section{Methods}

The ANSYS (Fluent) ${ }^{\mathrm{ab}}$ software package was used to numerically study the influence of velocity, density, and pressure on the emergency release of gas, which makes it possible to further determine the possible zones of damaging factors.

\subsection{Problem statement}

The internal diameter of gas pipeline, the actual preemergency gas pressure at the point of rupture, its size and location, and the time of emergency sections cut-off are the main parameters that affect the flow rate.

We modeled the "guillotine" rupture of the pipeline section at the full cross section (Fig. 1 a). The gap divides the gas pipeline of length $L$ into two equal emergency sections $L_{\mathrm{I}}$ and $L_{\mathrm{II}}$, for each section the mass gas flow rates $G_{1}(t)$ and $G_{2}(t)$ were calculated.

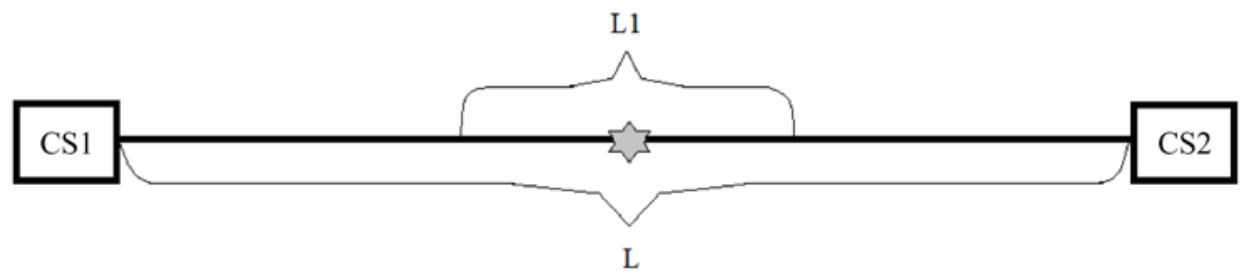

b)

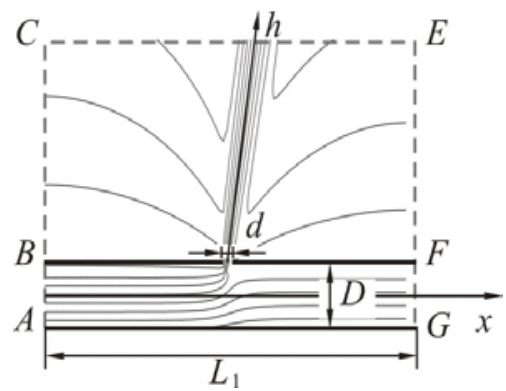

Fig. 1. Problem statement.

a diagram of the gas pipeline section between compressor stations CS1 and CS2 of length L; $\mathrm{b}$ - a fragment of the gas pipeline in the gap region (with jetlines)

\subsection{Mathematical model}

The gas flow through the gas pipeline is modeled in a stationary two-dimensional formulation using the ANSYS (FLUENT) software package. The channel geometry is shown in Fig. 1 b.

The basic equations of hydrodynamics for describing stationary turbulent flows are the Reynolds-averaged Navier-Stokes equations.

The motion equations are:

$$
\begin{aligned}
& v_{x} \frac{\partial v_{x}}{\partial x}+v_{y} \frac{\partial v_{x}}{\partial y}=-\frac{1}{\rho} \frac{\partial p}{\partial x}+\frac{1}{\rho} \frac{\partial}{\partial x}\left[\left(\mu+\mu_{T}\right) \frac{\partial v_{x}}{\partial x}\right]+\frac{\partial}{\partial y}\left[\left(\mu+\mu_{T}\right) \frac{\partial v_{x}}{\partial y}\right] \\
& v_{x} \frac{\partial v_{y}}{\partial x}+v_{y} \frac{\partial v_{y}}{\partial y}=-\frac{1}{\rho} \frac{\partial p}{\partial y}+\frac{1}{\rho} \frac{\partial}{\partial x}\left[\left(\mu+\mu_{T}\right) \frac{\partial v_{y}}{\partial x}\right]+\frac{\partial}{\partial y}\left[\left(\mu+\mu_{T}\right) \frac{\partial v_{y}}{\partial y}\right],
\end{aligned}
$$

where $v_{x}, v_{y}$ are the time-averaged projections of velocity vector on $x$ and $y$ coordinate axes, respectively, $\mathrm{m} / \mathrm{s} ; \quad p$ is the averaged hydrodynamic pressure, $\mathrm{Pa}$; $\mu=1.087 \cdot 10^{5} \mathrm{~Pa} \cdot \mathrm{s}$ is the dynamic coefficient of methane viscosity; $\rho=0.679 \mathrm{~kg} / \mathrm{m}^{3}$ is the methane density; $\mu_{\mathrm{T}}$ is the turbulent viscosity.

The continuity equation: 


$$
\frac{\partial v_{x}}{\partial x}+\frac{\partial v_{y}}{\partial y}=0
$$

The energy equation:

$v_{x} \frac{\partial T}{\partial x}+v_{y} \frac{\partial T}{\partial y}=\frac{\lambda}{c_{p} \rho}\left(\frac{\partial^{2} T}{\partial x^{2}}+\frac{\partial^{2} T}{\partial y^{2}}\right)+\frac{\partial}{\partial x}\left(a_{T} \frac{\partial T}{\partial x}\right)+\frac{\partial}{\partial y}\left(a_{T} \frac{\partial T}{\partial y}\right)$,

where $T$ is the averaged temperature, $\mathrm{K} ; \lambda=0.0332$ $\mathrm{W} /(\mathrm{m} \cdot \mathrm{K})$ is the heat conductivity; $c_{p}=2222 \mathrm{~J} /(\mathrm{kg} \cdot \mathrm{K})$ is the heat capacity; $a_{T}$ is the turbulent thermal diffusivity.

The basic system of motion equations (1) - (3) was closed by equations of the "standard" $k-\varepsilon$ turbulence model using the "standard" wall functions when modeling the flow in the boundary layer [9].

The equation of turbulent kinetic energy is:

$$
\begin{array}{r}
v_{x} \frac{\partial k}{\partial x}+v_{y} \frac{\partial k}{\partial y}=\frac{1}{\rho} \frac{\partial}{\partial x}\left[\left(\mu+\frac{\mu_{t}}{\sigma_{k}}\right) \frac{\partial k}{\partial x}\right]+\frac{1}{\rho} \frac{\partial}{\partial y}\left[\left(\mu+\frac{\mu_{t}}{\sigma_{k}}\right) \frac{\partial k}{\partial y}\right]- \\
-k\left(\frac{\partial v_{x}}{\partial x}+\frac{\partial v_{y}}{\partial y}\right)+G_{k}-\varepsilon-Y_{M}+S_{k},
\end{array}
$$

where $k$ is the kinetic turbulent energy; $\varepsilon$ is the dissipation of kinetic energy; $\mu_{\mathrm{T}}=C_{\mu} k^{2} / \varepsilon ; G_{k}=\mu_{\mathrm{T}} S^{2}$;
$C_{\mu}=0.09 ; \sigma_{k}=1.44$ are the empirical constants;

$S$ is the invariant of deformation tensor;

$Y_{M}=2 \varepsilon M_{T}^{2}$ is the input of alternating scattering to dissipation velocity at contraction turbulence;

$M_{T}=\sqrt{k / a^{2}}$ is the Mach number for turbulent gas;

$a=\sqrt{\gamma R T}=436 \mathrm{~m} / \mathrm{s}$ is the sound velocity at $T=281.7 \mathrm{~K}$;

$\gamma=1.385$ is the adiabatic index; $R=519 \mathrm{~J} /(\mathrm{kg} \cdot \mathrm{K})$ is the gas constant.

The equation of velocity of turbulent kinetic energy dissipation is:

$$
\begin{aligned}
v_{x} \frac{\partial \varepsilon}{\partial x}+v_{y} \frac{\partial \varepsilon}{\partial y}= & \frac{1}{\rho} \frac{\partial}{\partial x}\left[\left(\mu+\frac{\mu_{t}}{\sigma_{\varepsilon}}\right) \frac{\partial \varepsilon}{\partial x}\right]+\frac{1}{\rho} \frac{\partial}{\partial y}\left[\left(\mu+\frac{\mu_{t}}{\sigma_{\varepsilon}}\right) \frac{\partial \varepsilon}{\partial y}\right] \\
& -\varepsilon\left(\frac{\partial v_{x}}{\partial x}+\frac{\partial v_{y}}{\partial y}\right)+C_{1 \varepsilon} \frac{\varepsilon}{k} G_{k}-C_{2 \varepsilon} \frac{\varepsilon^{2}}{k}+S_{\varepsilon},
\end{aligned}
$$

where $C_{1 \varepsilon}=1.44 ; C_{2 \varepsilon}=1.92 ; \sigma_{\varepsilon}=1.3$.

The equations (1) - (5) are complemented with the following boundary conditions (see Fig. 1 b):

$A B:$

FG:

$$
p_{c}=7.5 \cdot 10^{6} ; p=p_{c}\left(1+\frac{\gamma-1}{2} M^{2}\right)^{\frac{\gamma}{\gamma-1}} ; M=1.64 \text { at } x=0 \text { and } 0<y<1.420
$$

$B C E F$ :

$$
p=7.5 \cdot 10^{6} \text { at } x=10 \text { and } 0<y<1.420 \text {; }
$$

$$
\begin{gathered}
p=101325 \text { at } x=0 \text { and } 1.420<y<20 \\
0<x<10 \text { and } y=20 \\
x=10 \text { and } 1.420<y<20
\end{gathered}
$$

$$
\begin{aligned}
& v_{x}=v_{y}=0 \text { at } 0<x<10 \text { and } y=0 \\
& 0<x<4.95 \text { and } y=1.420 \\
& 5.05<x<10 \text { and } y=1.42
\end{aligned}
$$

\section{Results and Discussion}

The gas outflow intensities were calculated according to the STO Gazprom 2-2.3-351-2009 methodology. The calculation results are shown in Table 1.

Table 1. The calculated gas outflow intensities

\begin{tabular}{|c|c|c|}
\hline \multicolumn{3}{|c|}{ Initial data: } \\
\hline Hyudraulic resistance & $\lambda$ & 0.0115 \\
\hline $\begin{array}{c}\text { Pipeline diameter, } \\
\text { mm }\end{array}$ & $\mathrm{D}_{0}$ & 1400 \\
\hline Pipeline length, km & $\mathrm{L}$ & 120 \\
\hline $\begin{array}{c}\text { Length of broken } \\
\text { segments, km }\end{array}$ & $\begin{array}{c}\mathrm{L}_{\mathrm{I}}, \\
\mathrm{L}_{\mathrm{II}}\end{array}$ & 60 \\
\hline $\begin{array}{c}\text { Temperature of } \\
\text { natural gas in } \\
\text { pipeline, } \mathrm{K}\end{array}$ & $\mathrm{T}_{1}{ }^{\mathrm{av}}$ & 281.7 \\
\hline
\end{tabular}

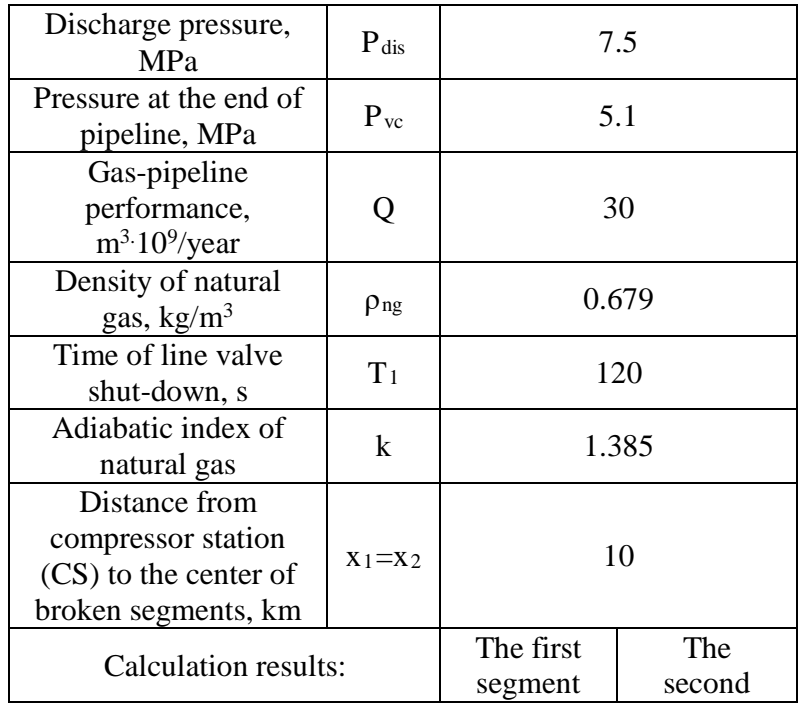




\begin{tabular}{|c|c|c|c|}
\hline & & & segment \\
\hline $\begin{array}{c}\text { Pressure at the } \\
\text { moment of accident at } \\
\text { the pipeline fracturing } \\
\text { point, MPa }\end{array}$ & $\mathrm{P}_{0}$ & \multicolumn{2}{|c|}{6.41} \\
\hline $\begin{array}{l}\text { The mass of gas that } \\
\text { is pumped into the } \\
\text { broken section of the } \\
\text { pipeline until the cut- } \\
\text { off, kg }\end{array}$ & Mcs & \multicolumn{2}{|c|}{82800.0} \\
\hline $\begin{array}{l}\text { The mass of gas in } \\
\text { the broken section of } \\
\text { the pipeline before } \\
\text { the accident, } \mathrm{kg}\end{array}$ & $\mathrm{Mg}_{\mathrm{g}}$ & 4186732.7 & 4021123.7 \\
\hline $\begin{array}{c}\text { The mass of gas } \\
\text { flowing in adiabatic } \\
\text { mode, } \mathrm{kg}\end{array}$ & $\mathrm{M}_{\mathrm{n}}$ & 341744.3 & 328227.4 \\
\hline $\begin{array}{l}\text { The initial critical gas } \\
\text { mass flow rate, } \mathrm{kg} / \mathrm{s}\end{array}$ & $\mathrm{G}_{0}$ & 17774.1 & 17774.1 \\
\hline Characteristics & $\eta_{\mathrm{L}}$ & 0.23 & 0.22 \\
\hline Time constant, s & $\varepsilon \mathrm{L}$ & 2038.7 & 2038.7 \\
\hline $\begin{array}{c}\text { Sound velocity in gas } \\
\text { before failure, m/s }\end{array}$ & $\mathrm{a}_{0}$ & 445.7 & 445.7 \\
\hline $\begin{array}{l}\text { The mass of gas } \\
\text { ejected from the } \\
\text { broken section at the } \\
\text { first stage of flowing, } \\
\text { kg }\end{array}$ & $\mathrm{M}_{1}$ & 448055.2 & 439980.4 \\
\hline $\begin{array}{l}\text { Gas consumption at } \\
\text { the time of closing the } \\
\text { linear valve, } \mathrm{kg} / \mathrm{s}\end{array}$ & $G\left(t_{L}\right)$ & 2821.1 & 2697.6 \\
\hline Time constant, s & $\varepsilon_{\mathrm{x}}$ & 138.7 & 138.7 \\
\hline Gas flow after & $\mathrm{G}(\mathrm{t})$ & 1830.3 & 1750.2 \\
\hline
\end{tabular}

\begin{tabular}{|c|c|c|c|}
\hline $\begin{array}{c}\text { blocking the linear } \\
\text { section }(\mathrm{t}-\mathrm{t} \mathrm{L})=60 \mathrm{~s}), \\
\mathrm{kg} / \mathrm{s}\end{array}$ & & & \\
\hline $\begin{array}{c}\text { The mass of gas } \\
\text { ejected from the } \\
\text { broken section at the } \\
\text { second stage of } \\
\text { flowing, } \mathrm{kg}\end{array}$ & $\mathrm{Mg}$ & 391250.9 & 374129.1 \\
\hline Total gas mass, $\mathrm{kg}$ & $\mathrm{M}$ & 839306.6 & 814109.5 \\
\hline
\end{tabular}

The dynamics of the total gas outflow from the two ends of pipeline is shown in Fig. 2. For the initial period of time $t=0.25 \mathrm{~min}$, the gas-contaminated zone is calculated. The length of a methane jet in unlimited airspace for the corresponding concentration limits does not exceed $600 \mathrm{~m}$ (Fig. 3).

During the underground gas pipeline rupture, a number of soil and pipe fragments are formed, their shape and direction of flight are random. It is generally accepted that the fragment motion directions are equally probable, the dispersion of fragments over the area depends only on the distance from the gas pipeline rupture site, and the zone of possible damage on the earth surface has the shape of a circle. The calculation of separation of soil fragments and pipe fragments was performed according to the STO Gazprom 2-2.3-3512009 methodology.

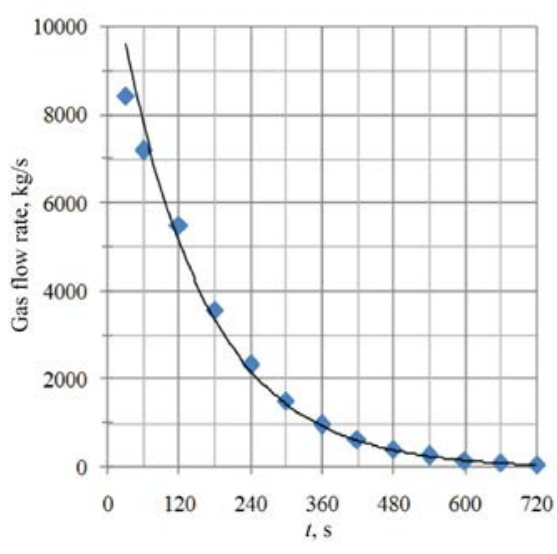

Fig. 2. The dynamics of the total flow of gas from two ends of the pipeline

It is assumed that part of the potential energy of the compressed gas is spent on fragmentation of the pipe jacket and soil layer, and getting of the initial velocity. In the future, the dynamics of movement of these fragments in the air is calculated, and the sizes of the zones (on the surface of the earth) of their scattering are determined. The calculation results are presented in table. 2.

Table 2. The calculation results of the parameters of a gas cloud formed during the expiration of a supersonic gas jet

\begin{tabular}{|c|c|c|}
\hline \multicolumn{3}{|c|}{ Initial data } \\
\hline $\begin{array}{c}\text { Pressure of the natural } \\
\text { gas in the pipeline, MPa }\end{array}$ & $\mathrm{P}_{\mathrm{p}}$ & 7.5 \\
\hline
\end{tabular}

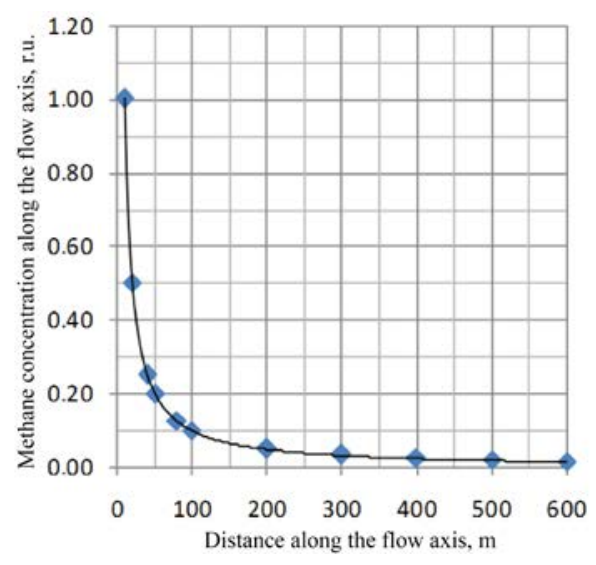

Fig. 3. The length of the jet at free flow at supercritical parameters into a stationary atmosphere at the time of flow $t=0.25$ $\min$

\begin{tabular}{|c|c|c|}
\hline $\begin{array}{c}\text { Atmospheric pressure, } \\
\mathrm{kPa}\end{array}$ & $\mathrm{P}_{\mathrm{c}}$ & 101.3 \\
\hline Pipeline diameter, mm & $\mathrm{D}_{0}$ & 1400 \\
\hline $\begin{array}{c}\text { Gas pipeline wall } \\
\text { thickness, mm }\end{array}$ & $\Delta \mathrm{p}$ & 21.5 \\
\hline $\begin{array}{c}\text { Density of natural gas, } \\
\mathrm{kg} / \mathrm{m}^{3}\end{array}$ & $\rho_{\mathrm{ng}}$ & 0.679 \\
\hline Density of soil, $\mathrm{kg} / \mathrm{m}^{3}$ & $\mathrm{P}_{\mathrm{p}}$ & 2000 \\
\hline $\begin{array}{c}\text { Density of the pipe } \\
\text { jacket material, } \mathrm{kg} / \mathrm{m}^{3}\end{array}$ & $\mathrm{P}_{\mathrm{p}}$ & 7800 \\
\hline $\begin{array}{c}\text { Adiabatic index of } \\
\text { natural gas }\end{array}$ & $\mathrm{k}$ & 1.385 \\
\hline
\end{tabular}




\begin{tabular}{|c|c|c|c|c|}
\hline Length of pipe break, m & \multicolumn{2}{|c|}{ Lbreak } & \multicolumn{2}{|c|}{10} \\
\hline Amount of fractures & \multicolumn{2}{|c|}{$\mathrm{N}_{\text {frac }}$} & & \\
\hline $\begin{array}{l}\text { The distance from the } \\
\text { axis of the gas pipeline } \\
\text { to the soil surface, } m\end{array}$ & \multicolumn{2}{|c|}{$\mathrm{H}$} & \multicolumn{2}{|c|}{1.0} \\
\hline \multicolumn{5}{|c|}{ Calculation results: } \\
\hline & $\mathrm{H} / \mathrm{R}$ & \multicolumn{3}{|c|}{2.43} \\
\hline $\begin{array}{c}\text { Density of gas in gas } \\
\text { pipeline, } \mathrm{kg} / \mathrm{m}^{3}\end{array}$ & $\rho_{\mathrm{g}, \mathrm{p}}$ & \multicolumn{3}{|c|}{51.93} \\
\hline Pressure difference, $\mathrm{Pa}$ & $\Delta \mathrm{P}$ & \multicolumn{3}{|c|}{7398700} \\
\hline Scattering work, J/kg & $\mathrm{Ag}_{\mathrm{g}}$ & \multicolumn{3}{|c|}{462528.75} \\
\hline & $\varphi$ & 30 & 45 & 60 \\
\hline & $\Delta \mathrm{H}$ & 1.40 & 0.99 & 0.81 \\
\hline Soil mass, kg & $\mathrm{M}_{\text {soil }}$ & 9705 & 11226 & 13775 \\
\hline $\begin{array}{l}\text { Initial velocity of soil (a } \\
\text { pipe fragment) tossing, } \\
\mathrm{m} / \mathrm{s}\end{array}$ & $\mathrm{V}_{0}$ & 58.94 & 48.02 & 37.23 \\
\hline
\end{tabular}

a)

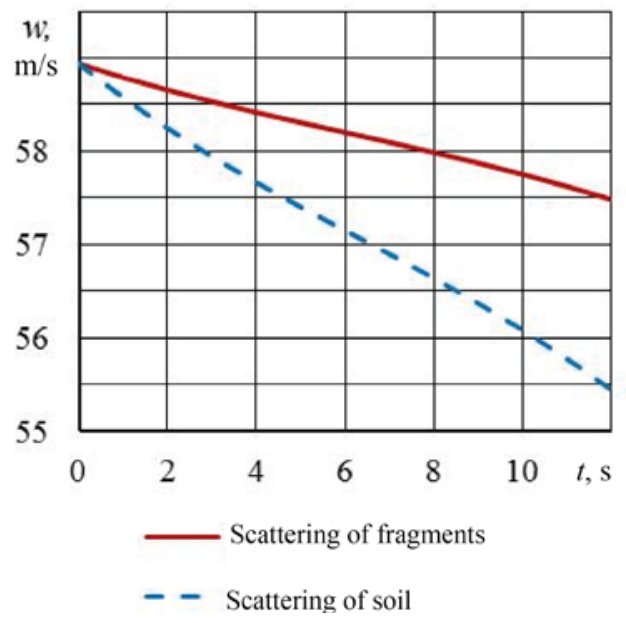

The equations for motion velocity of soil fragments and pipe jackets in air are given by a linear system of differential equations, which was solved by the fourthorder Runge-Kutta method.

Figure 4 presents the obtained graphical dependences of vertical and horizontal velocity components on the flight time of pipe and soil fragments at the opening angle of $\varphi=30^{\circ}$.

Knowing the dependences of velocity components, the numerical integration determines the timedependences of the flight range and the lift height of the emitted pipe fragment (soil):

Graphical dependences of flight range, lift height and flight time of a pipe fragment and soil at the same opening angle $\varphi=30^{\circ}$ are shown in Fig. 5.

b)

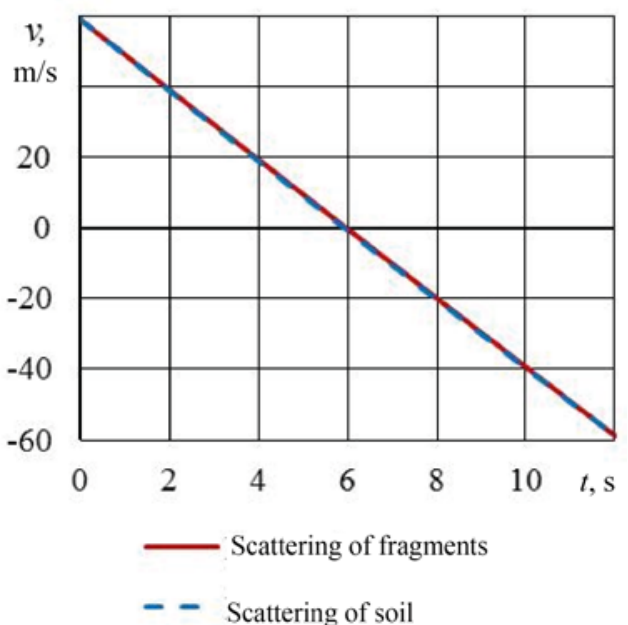

Fig. 4. Relationship between the scattering rate of fragments and soil on time a - vertical velocity components; b - horizontal velocity components

a)

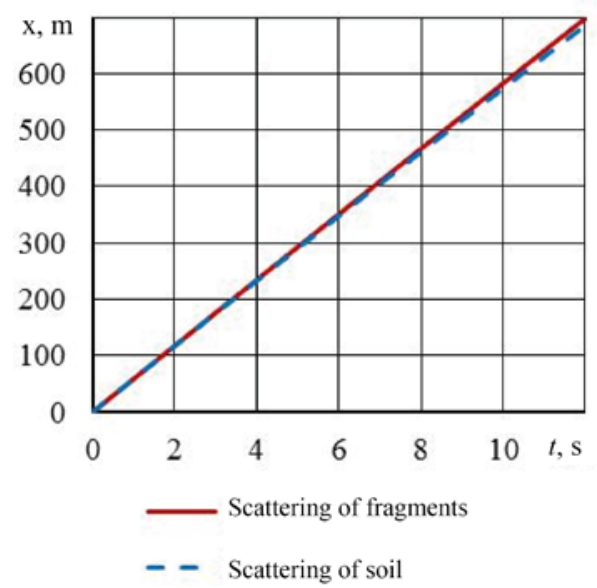

b)

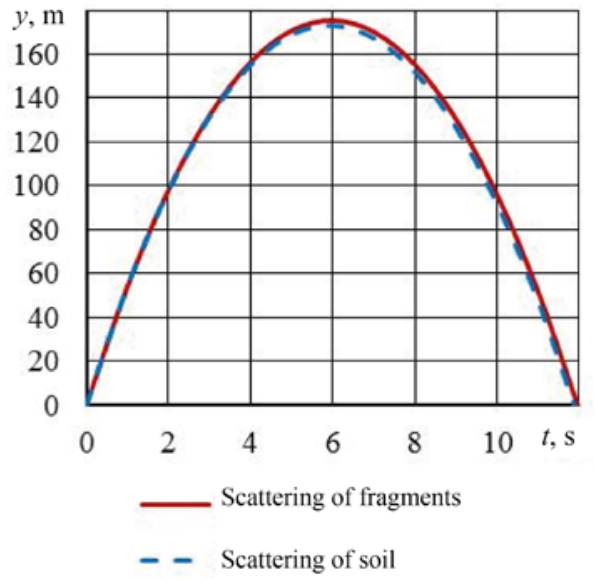

Fig. 5. Dependence of range and height of scattering of pipe and soil fragments on time: $a$ - range; $b$ - scattering height

By analyzing Figs. 4 - 5 we can draw the following conclusions:

- The velocity is linear along the $\mathrm{x}$ and $\mathrm{y}$ axes;

- For the initial velocity of tossing of soil (pipe fragment) $v_{0}=58.94 \mathrm{~m} / \mathrm{s}$ in about 12 seconds, soil fragments (pipes) reach the earth surface;
- Due to high pressure of the transported natural gas and the developed velocity, after rupture, soil fragments (pipes) can fly out into the atmosphere at sufficiently large distances, for example, at $700 \mathrm{~m}$ along the $\mathrm{x}$-axis and up to $180 \mathrm{~m}$ along the $\mathrm{y}$-axis. 
The obtained values make it possible to find the spatial distribution of the scattering parameters of fragments and soil (range, height and time), which makes it possible to assess the consequences of impacts (Fig. 6).

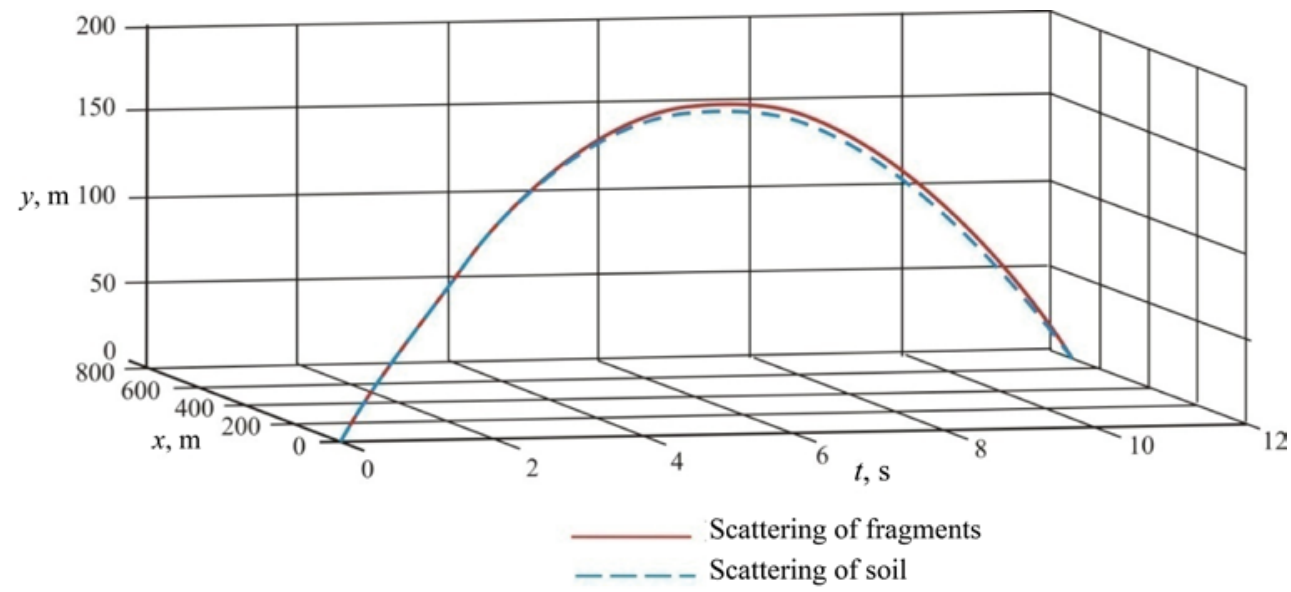

Fig. 6. Fragments and soil scattering trajectories at an accident

Table 3 shows the calculation of the fragmentation scattering range for fragment masses from $1 \mathrm{~g}$ to $1000 \mathrm{~kg}$ under the assumption that the fragments are compact (linear dimensions along the three orthogonal axes of the fragments are equal).

Table 3 The calculation of the scattering range of fragments

for different masses of fragments
\begin{tabular}{|c|c|c|c|}
\hline$P_{\mathrm{g}}$ & \multicolumn{3}{|c|}{$7.5 \mathrm{MPa}$} \\
\hline$H / R$ & \multicolumn{3}{|c|}{2.43} \\
\hline$\varphi$ & $30^{\circ}$ & $45^{\circ}$ & $60^{\circ}$ \\
\hline$m$ & \multicolumn{3}{|c|}{ Soil fragments } \\
\hline $1 \mathrm{~g}$ & 171 & 147 & 117 \\
\hline $1 \mathrm{~kg}$ & 507 & 370 & 242 \\
\hline $1 \mathrm{t}$ & 679 & 457 & 278 \\
\hline \multicolumn{4}{|c|}{ Pipe jacket fragments } \\
\hline $1 \mathrm{~g}$ & 292 & 237 & 174 \\
\hline $1 \mathrm{~kg}$ & 607 & 423 & 265 \\
\hline
\end{tabular}

a)

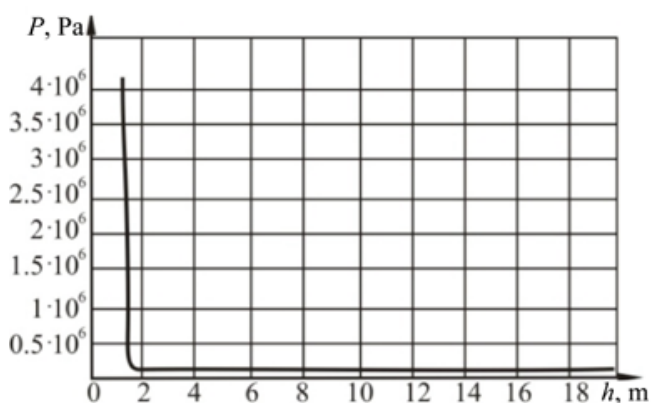

\begin{tabular}{|l|l|l|l|}
\hline $1 \mathrm{t}$ & 696 & 465 & 281 \\
\hline
\end{tabular}

Next, we numerically simulated a small-sized gap of the "wormhole" type of $d=0.1 \mathrm{~m}$, in a gas pipeline with a diameter of $D=1420 \mathrm{~mm}$, in a section with a length of $L_{1}=10 \mathrm{~m}$ and the operation transportation pressure of $P=7.5 \mathrm{MPa}$ (Fig. $1 \mathrm{~b}$ ).

According to the obtained results, if methane in amount of $Q_{\text {in }}=646 \mathrm{~kg} / \mathrm{s}$ is transported through the pipe in a stationary mode, then $Q_{\text {out }}=232 \mathrm{~kg} / \mathrm{s}$ is emitted into the atmosphere, and only $Q_{\text {pot }}=414 \mathrm{~kg} / \mathrm{s}$ comes to the consumer after a break. Fig. 7 presents the results of calculation the distribution of static and total pressure over the height of scattering. As it can be seen from the graphs, the gas pressure at the break point is $P=4.3 \mathrm{MPa}$ and at a height approximately equal to $h=2$ $\mathrm{m}$ the pressure is equal to atmospheric (Fig. $7 \mathrm{a}$ ).

Fig. 7. Pressure distribution along the scattering axis

$a$ - change in static pressure over the height; $b$ - change in total pressure over the height

Fig. 8 shows the distribution of velocities along the axis of the ejected jet and along the axis of the pipeline.
Due to changes in the flow rate in the gas pipeline, the gas velocity significantly drops after the rupture point 
(Fig. 8 a), but the jet velocity, on the contrary, remains quite high even at a height of $h=20 \mathrm{~m}$ (Fig. $8 \mathrm{~b}$ ). The gas velocity at the discontinuity point is $|\mathrm{v}|=2662 \mathrm{~m} / \mathrm{s}$. a)

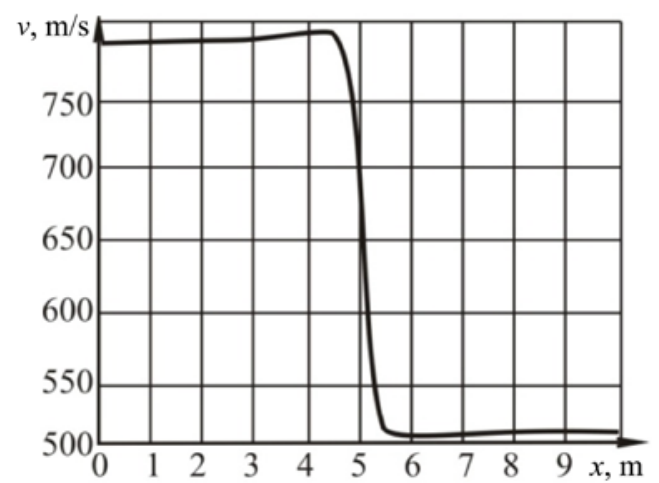

b)

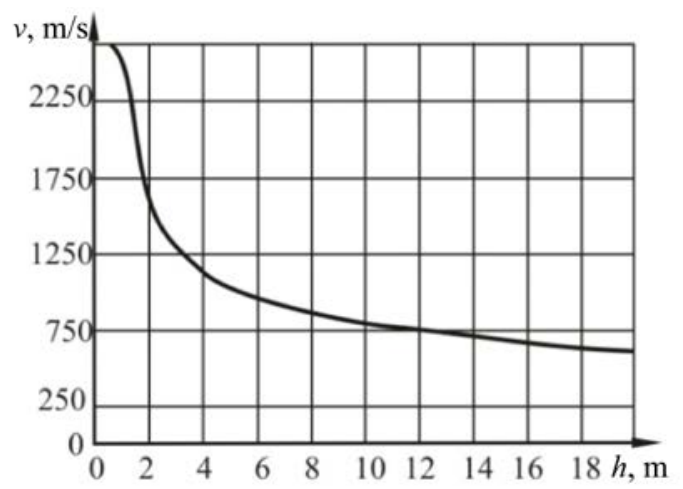

Fig. 8. Distribution of velocities:

$a$ - change in velocity along the pipeline axis; $b$ - change in velocity over the height

\section{Conclusions}

The emergency pipeline rupture was simulated using the ANSYS (FLUENT) software package. A numerical experiment on a stationary gas (methane) outflow from a high pressure gas pipeline $(P=7.5 \mathrm{MPa})$ and $D=1420$ $\mathrm{mm}$ was carried out. The dependences of distribution of the total pressure and velocity along the axis of the gas ejection are obtained. The calculation results are presented graphically.

The results of numerical study allow us to develop a multivariate test problem for emergency depressurization of gas pipelines, which is relevant for solving applied problems of risk analysis at designing gas pipelines.

\section{References}

1. V.E. Seleznev, V.V. Aleshin, S.N. Pryalov, MAKS Press. 436. (2009)

2. V. Kurushina, Y. Zemenkov Energy Production and Management in the 21st Century Vol.2 WIT Press, Southampton Boston. (2014)

3. T.A. Zubairov, B.N. Mastobaev, M.M. Fattakhov, Transport and storage of petroleum products and hydrocarbons. 3 (2014).

4. A.I. Kuptsov, F.M. Gimranov, Ministry of education and science of Russia. Kazan National research Technological University. Kazan: Publishing House of the Academy of Sciences of the Republic of Tajikistan. 136. (2018)

5. M.N. Ortina, A.I. Kuptsov, F.M. Gimranov, Bulletin of the Technological University. 20, 10. (2017)

6. J. M. Santos, N. C. Reis, E. V. Goulart, and I. Mavroidis, Atmos. Environ. (2009)

7. S. M. Tauseef, D. Rashtchian, T. Abbasi, and S. A. Abbasi, J. Loss Prev. Process Ind. (2011)

8. A. Ebrahimi-Moghadam, M. Farzaneh-Gord, and M.
Deymi-Dashtebayaz, J. Nat. Gas Sci. Eng. (2016)

9. L. Xinhong, C. Guoming, Z. Renren, Z. Hongwei, and F. Jianmin, Process Saf. Environ. Prot. (2018)

10.A. Ebrahimi-Moghadam, M. Farzaneh-Gord, A. Arabkoohsar, and A. J. Moghadam, J. Clean. Prod. (2018)

11.P. L. Metropolo and A. E. P. Brown, Process Saf. Prog. (2004)

12. B. Rothwell and M. Stephens, in Proc. Bienn. Int. Pipeline Conf. IPC (2007)

13.K. F. Tee, K. Pesinis, and T. Coolen-Maturi, Int. J. Press. Vessel. Pip. (2019)

14.D. H. Kim, M. Gautam, and D. Gera, Atmos. Environ. (2001)

15.B. Blocken, T. Stathopoulos, P. Saathoff, and X. Wang, J. Wind Eng. Ind. Aerodyn. (2008)

16.T. L. Chan, G. Dong, C. W. Leung, C. S. Cheung, and W. T. Hung, Atmos. Environ. (2002)

17.M. Pontiggia, M. Derudi, V. Busini, and R. Rota, J. Hazard. Mater. (2009)

18. J.M. Crowther, A.G.A.A. Hassan, Water, Air and Soil pollution: Focus. 2. (2002)

19.S.P. Arya. Press New York. (2001)

20. J. E. Pieterse and T. M. Harms, J. Wind Eng. Ind. Aerodyn. (2013)

21. C. Alinot and C. Masson, in J. Sol. Energy Eng. Trans. ASME (2005)

22.A. Parente, C. Gorlé, J. van Beeck, and C. Benocci, J. Wind Eng. Ind. Aerodyn. (2011) 